
\title{
Resesarch Sulure \\ Research on Ultrasonic Vibration Assisted Electrical Discharge Machining SiCp/Al Composite
}

\author{
Xiang Gao \\ Shandong University \\ Jucai Li \\ Shandong University \\ Qixuan Xing \\ Shandong University \\ Qinhe Zhang ( $\nabla$ zhangqh@sdu.edu.cn ) \\ Shandong University
}

\section{Research Article}

Keywords: SiCp/Al composites, EDM, Ultrasonic vibration, Simulation of gap flow field

Posted Date: September 7th, 2021

DOI: https://doi.org/10.21203/rs.3.rs-870246/v1

License: (c) (i) This work is licensed under a Creative Commons Attribution 4.0 International License. Read Full License 


\title{
Research on Ultrasonic Vibration Assisted Electrical Discharge Machining SiCp/Al
}

\section{Composite}

\author{
Xiang Gao ${ }^{1,2}$, Jucai Li ${ }^{1,2}$, Qixuan Xing ${ }^{1,2}$, Qinhe Zhang ${ }^{1,2}$ * \\ ${ }^{1}$ Key Laboratory of High Efficiency and Clean Mechanical Manufacture (Ministry of Education), \\ School of Mechanical Engineering, Shandong University, Jinan 250061, China \\ ${ }^{2}$ National Demonstration Center for Experimental Mechanical Engineering Education, Shandong \\ University, Jinan 250061, China \\ ${ }^{*}$ Corresponding author. E-mail address: zhangqh@sdu.edu.cn Tel.: +86-531-88392850
}

\begin{abstract}
In this paper, ultrasonic-vibration assisted electrical discharge machining (UEDM) is used to process $\mathrm{SiCp} / \mathrm{Al}$ composite materials in order to achieve a higher material removal rate (MRR) and lower surface roughness, width overcut, and relative tool wear rate (RTWR). FLUENT software was used to simulate the gap flow field. The simulation results of the gap flow field show that the ultrasonic vibration of the tool electrode is conducive to the removal of chips, which makes the discharge more stable and improves the machining efficiency. Based on the single factor experiment, the effects of peak current, reference voltage, pulse width, and pulse interval on MRR, surface roughness, width overcut, and RTWR of the workpiece are studied. Then, based on the orthogonal experiment, the grey relational analysis method was used to optimize the process parameters, and the order of the influence of the 4 process indicators on the comprehensive performance and the optimal processing parameter combination was obtained. The reliability of the process optimization was verified with experiments.
\end{abstract}

Keywords: SiCp/Al composites; EDM; Ultrasonic vibration; Simulation of gap flow field;

\section{Introduction}

$\mathrm{SiCp} / \mathrm{Al}$ composite material composite materials have significant advantages in terms of specific stiffness, specific strength, solderability, and thermal conductivity, and are widely used in the fields of automobiles, electronics, and aerospace $[1,2] . \mathrm{SiCp} / \mathrm{Al}$ composite material is used to manufacture special nuts in the solar cell wing deployment mechanism because of its excellent performance. In order to make the nut lighter, square holes need to be machined on its side, as shown in Figure 1. However, the SiC particles in SiCp/Al make its machining difficult [3]. 


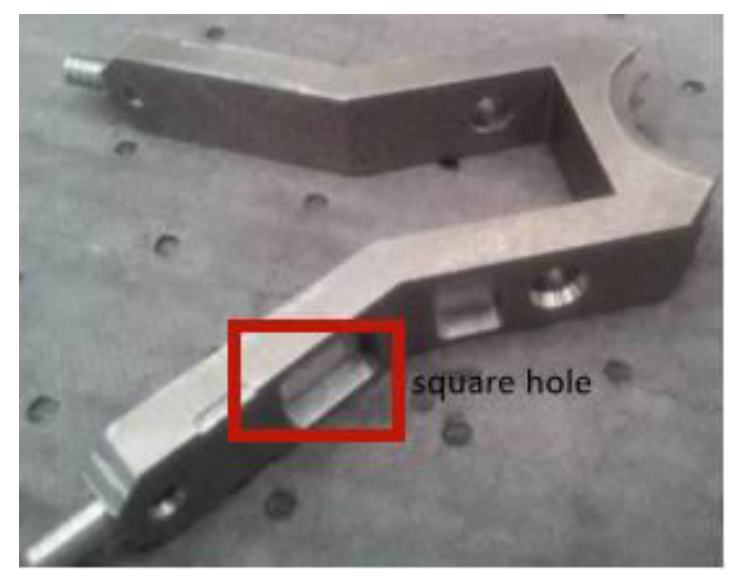

Figure 1 Special nut in the solar battery wing deployment mechanism

Electrical discharge machining (EDM) is a method of processing materials using the heat generated by electrical discharge, so the hardness has little effect on the processing effect [4]. Zhang $\mathrm{H}$ et al. [5] conducted micro-hole machining experiments on $\mathrm{SiCp} / \mathrm{Al}$ composite materials using EDM and obtained the influence of voltage on machining accuracy and surface roughness. Micro-holes with $53 \mu \mathrm{m}$ were successfully processed in the experiment. Liu Y et al. [6] established a single-pulse discharge model of $\mathrm{SiCp} / \mathrm{Al}$ composite material and analyzed the changes in temperature field and the formation of molten pool during the processing of $\mathrm{SiCp} / \mathrm{Al}$ composite materials. The experimental results show that if the pulse width increases, the depth-to-diameter ratio of the molten pool will decrease, but the increase of the peak current will reduce the depthto-diameter ratio of the molten pool. Senapati N P et al. [7] analyzed the influence of process parameters on MRR, tool wear rate and surface roughness through the experiment of EDM machining $\mathrm{SiCp} / \mathrm{Al}$ composites. At the same time, the feasibility of using EDM to process $\mathrm{SiCp} / \mathrm{Al}$ composites was proved. Although many scholars have proved that EDM can be used to process difficult machining materials such as $\mathrm{SiCp} / \mathrm{Al}$, there still exist some problems in the machining process, such as low machining efficiency, unstable discharge and so on [8-10].

The $\mathrm{SiCp} / \mathrm{Al}$ composite material contains $\mathrm{SiC}$ ceramic particles. The $\mathrm{SiC}$ particles have strong thermal resistance, which causes the $\mathrm{SiC}$ particles unable to be eroded away but remain in the discharge area of the two electrodes. This will cause the discharge unstable, thereby affecting the processing efficiency. Therefore, improving the chip removal ability is of great significance for EDM [11]. Studies have shown that the chip removal ability of EDM will be significantly improved due to the auxiliary effect of ultrasonic vibration. At present, many scholars use 
ultrasonic vibration to improve the chip removal ability of EDM. Liu Y et al. [12] simulated the chip removal process of UEDM, and the results showed that the debris in UEDM was greatly reduced compared with EDM. Wang Y et al. [13] studied the material removal mechanism of UEDM based on the principle of heat transfer, and analyzed the influence of UEDM on machined surface through the established single-pulse removal model. The conclusion is that the surface roughness will be reduced due to the auxiliary effect of ultrasonic vibration. Shabgard M R et al. [14] studied the effect of applying ultrasonic vibration to the tool electrode on the EDM based on the finite element method. The results show that UEDM can effectively improve the material removal rate compared with EDM. Shitara T et al. [15] observed the discharge phenomenon in UEDM through a high-speed camera, and obtained similar conclusions. Shervani-Tabar M T et al. [16] studied the dynamic behavior of steam bubbles generated by ultrasonic vibration, it was proved from different angles that UEDM can improve the material removal rate.

Although it has been generally recognized that the auxiliary effect of ultrasonic vibration can speed up chip removal and improve processing efficiency [17, 18], but currently, there are few studies on UEDM processing $\mathrm{SiCp} / \mathrm{Al}$. In this paper, by studying the effect of process parameters on the processing effect when UEDM is processing $\mathrm{SiCp} / \mathrm{Al}$, it is beneficial to realize the engineering application of UEDM processing $\mathrm{SiCp} / \mathrm{Al}$. And through the optimization of processing parameters, the processing efficiency and processing quality can be improved [19]. Therefore, this research has important practical significance.

In this paper, fluid mechanics simulation software was used to simulate and calculate the medium flow field and the movement of erosion particles in the UEDM. Through simulation calculation, Compared with EDM, the working fluid in UEDM flows faster, which helps to reduce the occurrence of short circuit and secondary discharge. Combining single factor experiment and orthogonal experiment design method, the process experiment research of UEDM machining $\mathrm{SiCp} / \mathrm{Al}$ composite material square hole was carried out, and the grey correlation analysis method was introduced to find the combination of machining parameters that optimize the comprehensive performance of machining.

\section{Simulation of Gap flow field}

In UEDM, the ultrasonic vibration of the tool electrode is usually better for the chip removal because it will promote the flow of the working medium. This paper carried out the flow field 
simulation of the machining gap to verify the effect and feasibility of UEDM processing SiCp/Al using the FLUENT simulation software.

\subsection{Simulation model and condition setting}

\subsubsection{Calculation of machining gap}

The size of the discharge gap will affect the discharge parameters in UEDM, so it is difficult to accurately measure. The empirical formula for the bottom clearance value is as follows [20]:

$$
S=K_{V} \cdot V+K_{R} \cdot \varepsilon_{0}^{0.4}+A_{m}
$$

In this formula, $K_{V}$ is the coefficient related to the dielectric constant of the working fluid, where the working fluid is kerosene, taking $5 \times 10^{-2} . V$ is the open-circuit voltage, taking the value 100V. $K_{R}$ is the coefficient related to the processing material, which taking the value $2.5 \times 10^{2}$ according to the processing material. $A_{m}$ is the mechanical gap, which is $3 \mu \mathrm{m} . \varepsilon_{0}$ is the single pulse discharge energy, the formula is as follows:

$$
\varepsilon_{0}=\int_{0}^{t_{e}} u(t) \cdot i(t) d t \approx u_{e} \cdot i_{e} \cdot t_{e}
$$

Where, $u_{e}$ is the spark discharge sustain voltage, which is $25 \mathrm{~V} ; i_{e}$ is the pulse peak current, which is $37 \mathrm{~A} ; t_{e}$ is the pulse width, which is $100 \mu$ s.

According to the above parameters and formulas, the machining gap is calculated to be $104.5 \mu \mathrm{m}$. This chapter is a numerical simulation of the effect of the gap flow field and the movement of the erosion particles, so the discharge breakdown and other factors are not considered. The bottom machining gap is set to $100 \mu \mathrm{m}$, and the side machining gap is set to $200 \mu \mathrm{m}$.

\subsubsection{Mesh model creation}

The length of the tool electrode is $15.6 \mathrm{~mm}$, and the gap flow field with a processing depth of $3 \mathrm{~mm}$ is simulated using WORKBENCH software. When the flow field is simulated, different areas will be divided into different meshes. The part close to the tool electrode is the main area of this simulation and the speed and pressure of this part change greatly, so the grid is relatively fine, and the grid size of other parts is appropriately increased. Figure 2 shows the established mesh model. 


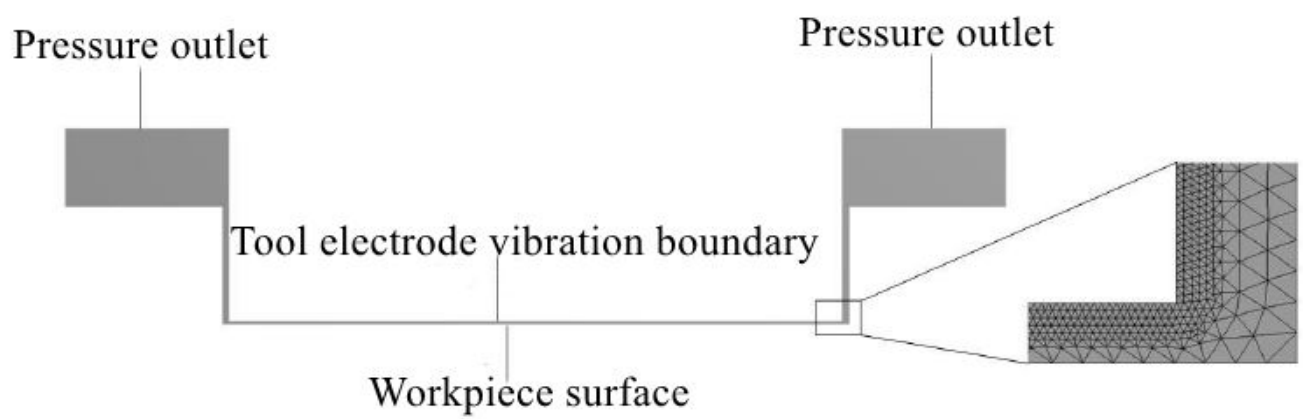

Figure 2 Interstitial flow field grid model

\subsection{Simulation results and analysis}

\subsubsection{The effect of tool vibration on the velocity of the flow field}

The following is the displacement formula of the tool electrode:

$$
\begin{gathered}
s=A \sin (\omega t) \\
\omega=2 \pi f
\end{gathered}
$$

In this formula, $s$ is the displacement of the tool electrode; $\mathrm{A}$ is the peak of the tool electrode displacement, and here is $3 \mu$; $f$ is the electrode vibration frequency, and its value is $28.3 \mathrm{KHz}$. $\omega$ is the angular frequency of electrode vibration.

The derivative function of formula 3 is the velocity of the tool electrode, and the formula is as follows:

$$
v=2 \pi f A \cos (2 \pi f t)
$$

The change of the flow field velocity in the machining gap at different moments of the vibration cycle is shown in Figure 3. When $t$ is $(0, \pi / 2)$ or $(3 \pi / 2,2 \pi)$, the tool electrode is far away from the surface of the workpiece, the bottom gap increases, and the liquid medium flows into the gap. Then the working fluid in the gap flows out. The fluid velocity in the machining gap has the same changing law as the electrode velocity, which can be seen from Figure 3. The auxiliary effect of ultrasonic vibration will affect the speed of the working fluid in the gap, which is conducive to the discharge of debris. 


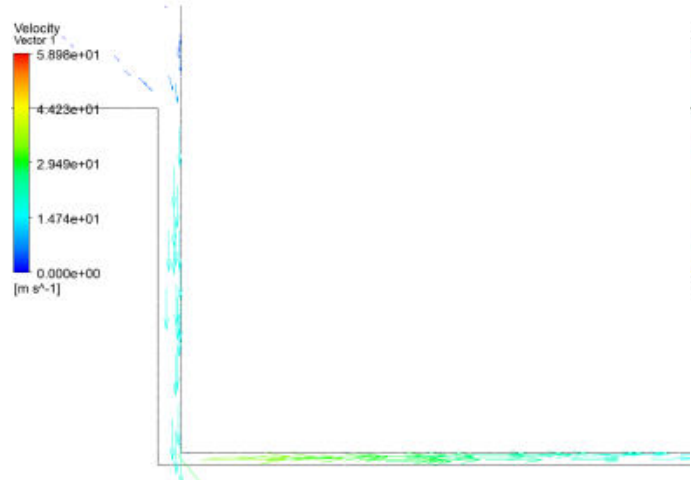

(a) $t=\pi / 10$

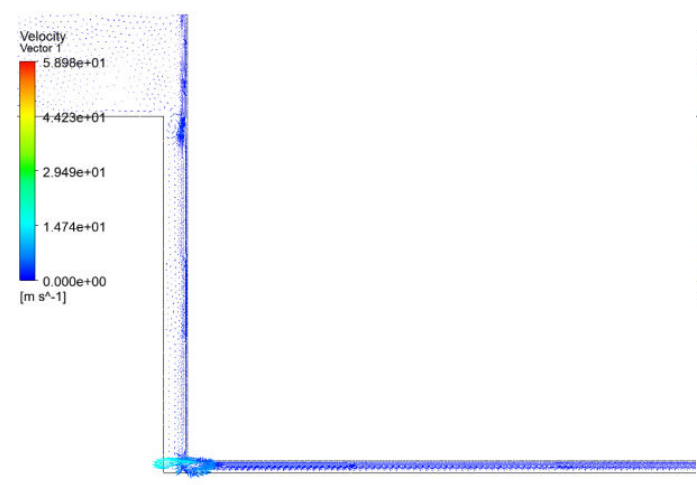

(c) $t=\pi / 2$

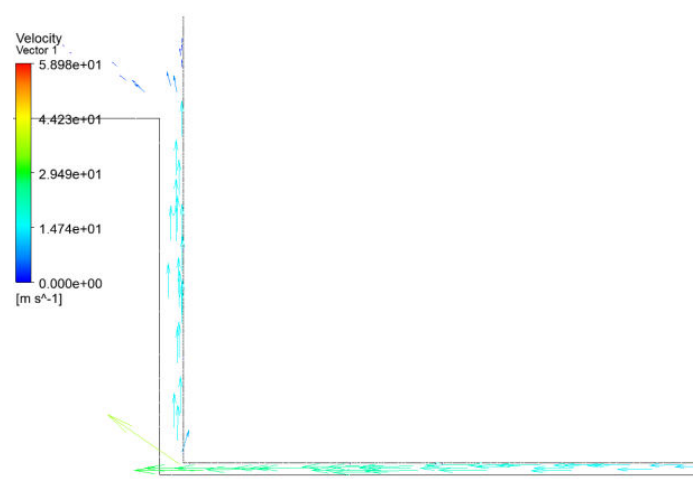

(e) $t=4 \pi / 5$

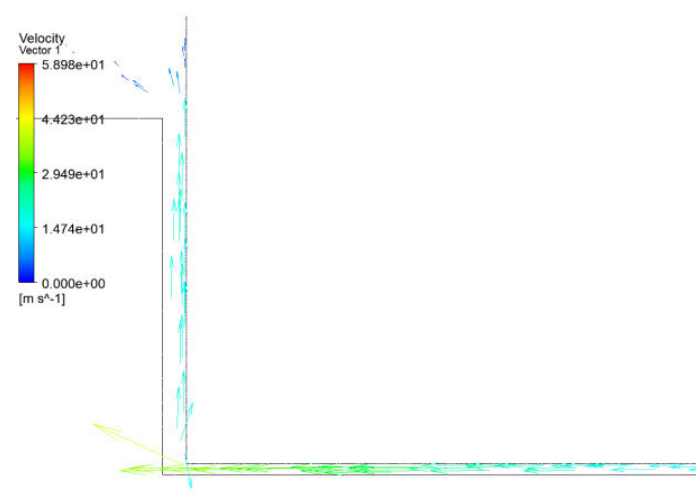

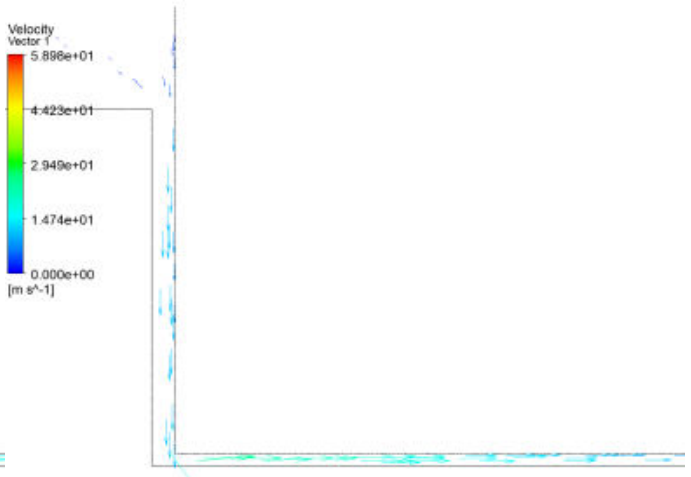

(b) $t=3 \pi / 10$

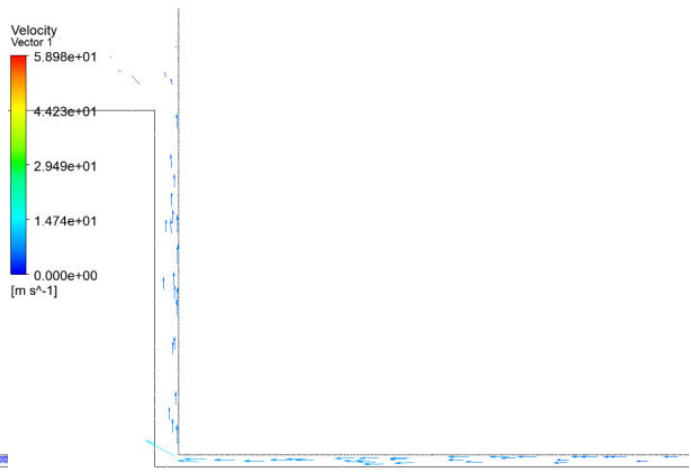

(d) $t=3 \pi / 5$

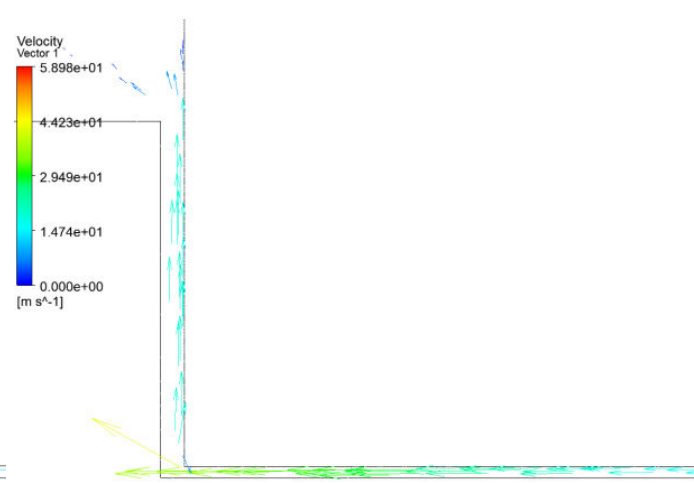

(f) $t=\pi$

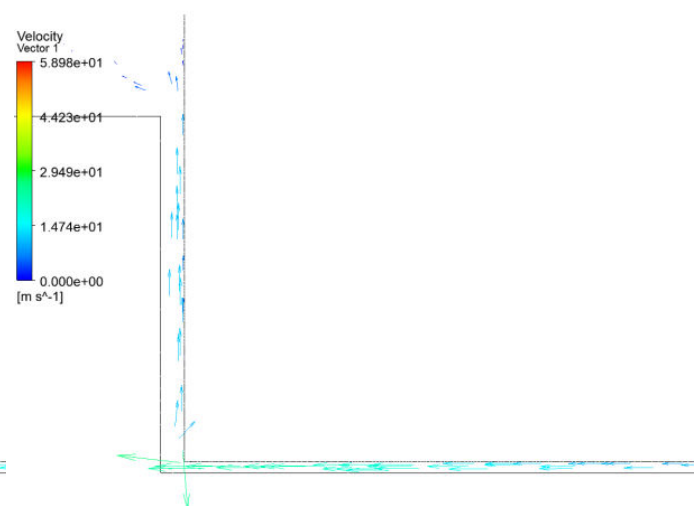


(g) $\mathrm{t}=11 \pi / 10$

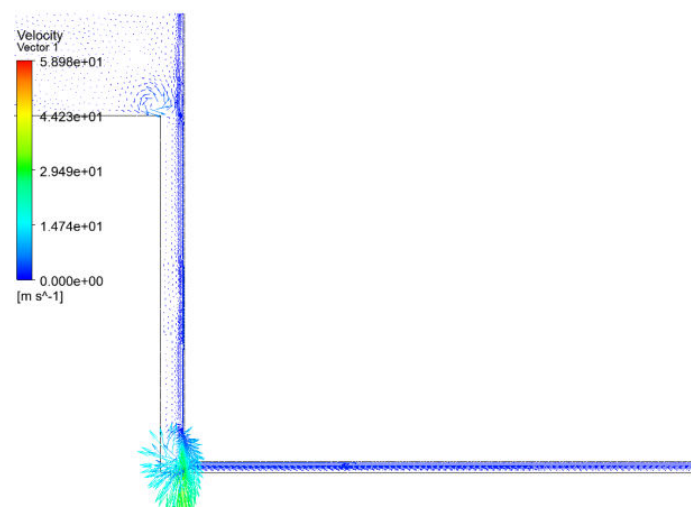

(i) $t=3 \pi / 2$

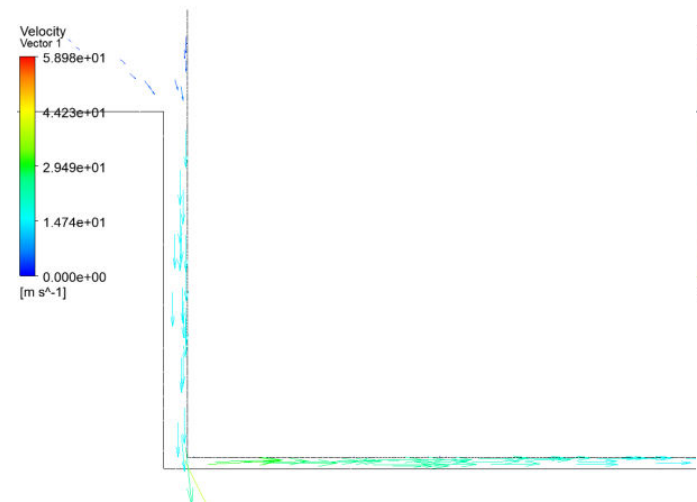

(k) $\mathrm{t}=9 \pi / 5$ (h) $\mathrm{t}=13 \pi / 10$

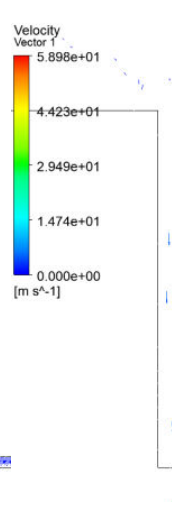

(j) $\mathrm{t}=8 \pi / 5$

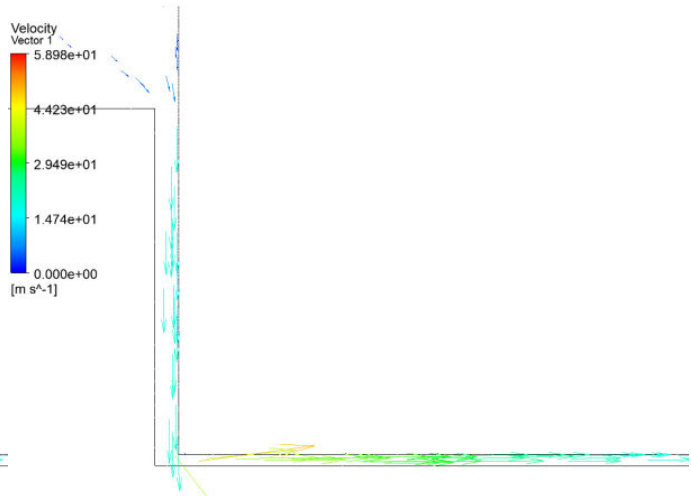

(1) $t=2 \pi$

Figure 3 Flow field velocity change diagram of a single ultrasonic vibration cycle

\subsubsection{The effect of tool vibration on the debris}

The distribution of debris at different times during the UEDM process is shown in Figure 4. We can see from Figure 4 that the debris is distributed at the bottom of the machining gap due to gravity when the ultrasonic vibration of the tool electrode stops. After ultrasonic vibration was applied to the tool electrode, the debris begins to move due to the disturbance of the working fluid and will finally be discharged.

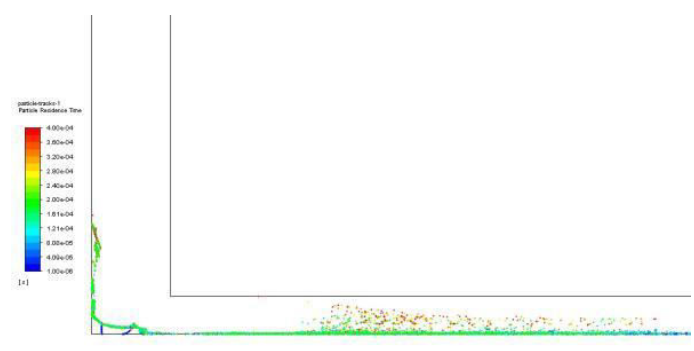

(a) $\mathrm{t}=400 \mu \mathrm{s}$

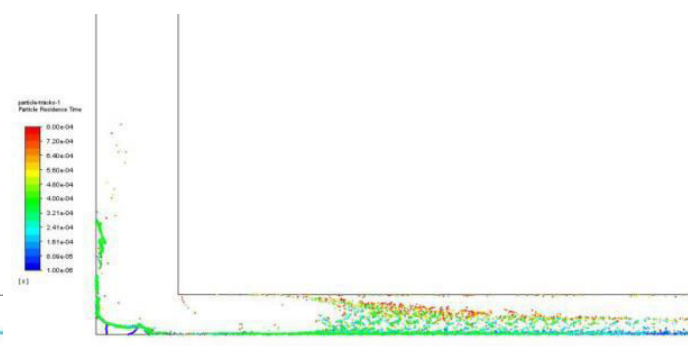

(b) $t=800 \mu \mathrm{s}$ 


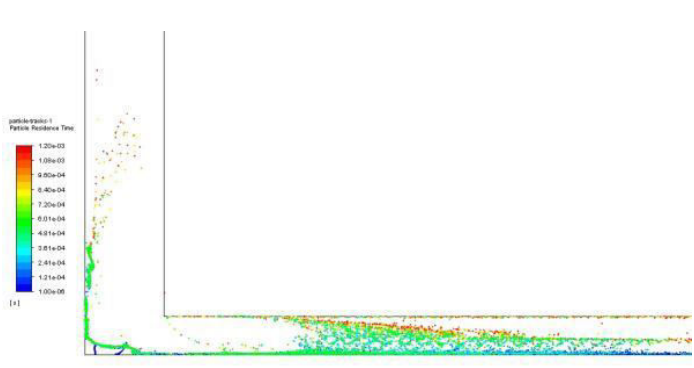

(c) $\mathrm{t}=1200 \mu \mathrm{s}$

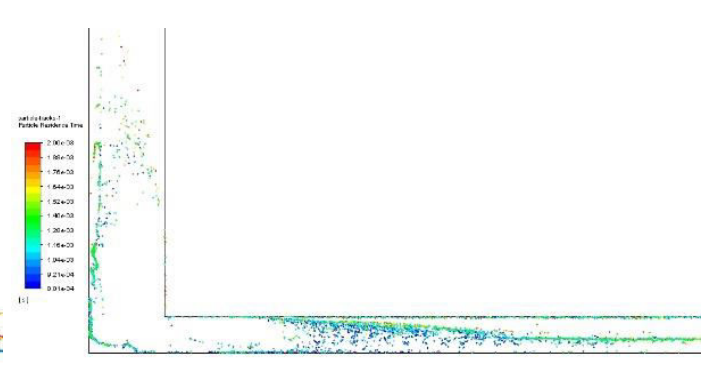

(d) $\mathrm{t}=2000 \mu \mathrm{s}$

Figure 4 Distribution diagram of erosion particles

\section{Experiment setup and methods}

\subsection{Experiment platform}

This experiment was carried out on the AgieCharmilles EDM machine SF201. The vertical resolution of the $\mathrm{Z}$-axis of the machine tool is $1 \mu \mathrm{m}$, the resonance frequency of the ultrasonic vibration spindle is $28.3 \mathrm{kHz}$, and the amplitude is $3 \mu \mathrm{m}$. In this paper, the experiment of $\mathrm{SiCp} / \mathrm{Al}$ composite forming square hole processing was carried out on this platform. Table 1 is the basic parameter in this experiment.

Table 1 Experimental parameters

\begin{tabular}{cc}
\hline Project & Value or condition \\
\hline Workpiece & $20 \%$ volume fraction of SiCp/Al composite plate \\
Tool electrode & Copper with a bottom size of $15.6 \mathrm{~mm} \times 13.6 \mathrm{~mm}$ \\
Working fluid & Spark oil \\
Liquid supply method & Immersion \\
Processing polarity & Electrode connected to negative electrode \\
Processing depth & $4 \mathrm{~mm}$ \\
\hline
\end{tabular}

\subsection{Design of single-factor experimental}

Through single factor experiments, we studied the effects of peak current, reference voltage, pulse interval, and pulse width on MRR, surface roughness, width overcut, and RTWR. Table 2 shows the value of each factor level of the single factor experiment. The basic level is peak current $37 \mathrm{~A}$, reference voltage $70 \mathrm{~V}$, pulses interval $75 \mu \mathrm{s}$, and pulse width $100 \mu \mathrm{s}$. Each set of experimental data is tested three times to ensure the reliability of the results.

Table 2 Factor level table

\begin{tabular}{ccc}
\hline Processing parameters & Basic level & Each parameter level \\
\hline Peak current $/ \mathrm{A}$ & 37 & $5.6,18.4,37,50,64$ \\
The reference voltage $/ \mathrm{V}$ & 70 & $52,60,65,70,80$ \\
Pulse interval $/ \mu \mathrm{s}$ & 75 & $32,56,75,130,240$ \\
Pulse Width $/ \mu \mathrm{s}$ & 100 & $56,100,300,750,1800$ \\
\hline
\end{tabular}

\subsection{Design of orthogonal experiment}


An orthogonal experiment can use a relatively small number of experiments to obtain better results and achieve the purpose of the experiment. Optimization based on orthogonal experiments usually has better results. The orthogonal experiment in this paper is carried out on the basis of single factor experiment, Table 3 lists the parameters' values. Table 4 shows the test parameters of the orthogonal experiment.

Table 3 Factor level table

\begin{tabular}{ccccc}
\hline Level & $\begin{array}{c}\text { Pulse width } \\
(\mu \mathrm{s})\end{array}$ & $\begin{array}{c}\text { Pulse interval } \\
(\mu \mathrm{s})\end{array}$ & $\begin{array}{c}\text { Peak current } \\
(\mathrm{A})\end{array}$ & $\begin{array}{c}\text { The reference voltage } \\
(\mathrm{V})\end{array}$ \\
\hline 1 & 56 & 32 & 18.4 & 60 \\
2 & 320 & 75 & 37 & 70 \\
3 & 1800 & 240 & 64 & 80 \\
\hline \multicolumn{7}{c}{ Table 4 Orthogonal test scheme } \\
\hline Serial & Pulse width & Pulse interval & Peak current & The reference voltage \\
number & $(\mu \mathrm{s})$ & $(\mu \mathrm{s})$ & $(\mathrm{A})$ & $(\mathrm{V})$ \\
\hline 1 & 56 & 32 & 18.4 & 60 \\
2 & 56 & 75 & 37 & 70 \\
3 & 56 & 240 & 64 & 80 \\
4 & 320 & 32 & 37 & 60 \\
5 & 320 & 75 & 64 & 70 \\
6 & 320 & 240 & 18.4 & 80 \\
7 & 1800 & 32 & 64 & 60 \\
8 & 1800 & 75 & 18.4 & 37 \\
9 & 1800 & 240 & 37 & \\
\hline
\end{tabular}

According to the data in Table 4, three trials for each set of data.

\section{Results and analysis of single-factor test}

\subsection{Effect of peak current on UEDM}

Under the premise that other experimental conditions remain unchanged, change the magnitude of the peak current to study its influence on MRR, surface roughness, width overcut, and RTWR. Figure 5 is the relationship curve between peak current and UEDM index. We can see from the figure that after the peak current increases, the MMR, surface roughness, width overcut and RTWR also increase. Figure 6 shows the microscopic surface morphology of the square holes formed by UEDM in SiCp/Al composites when the peak currents are different. 


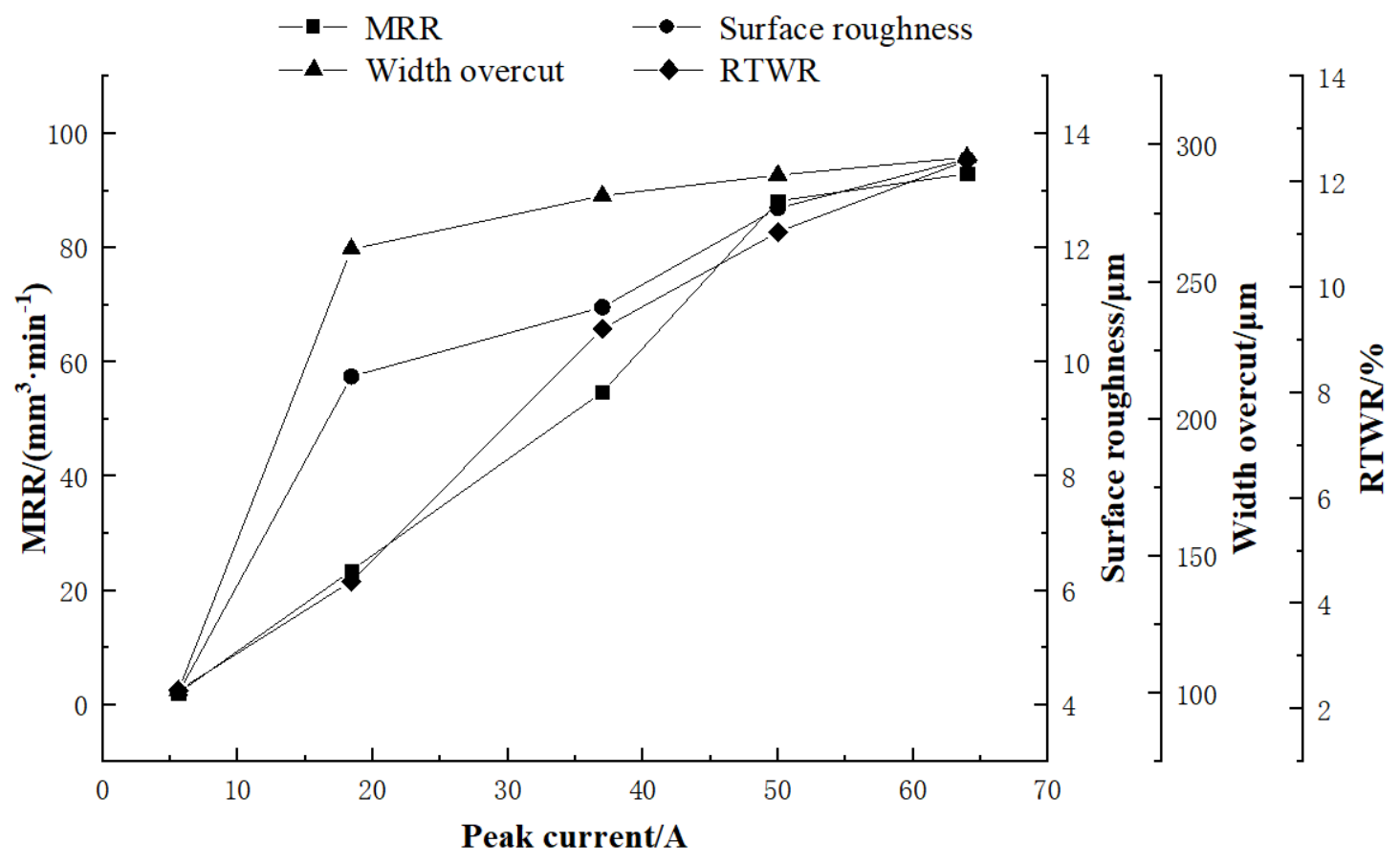

Figure 5 The influence of peak current on processing indexes

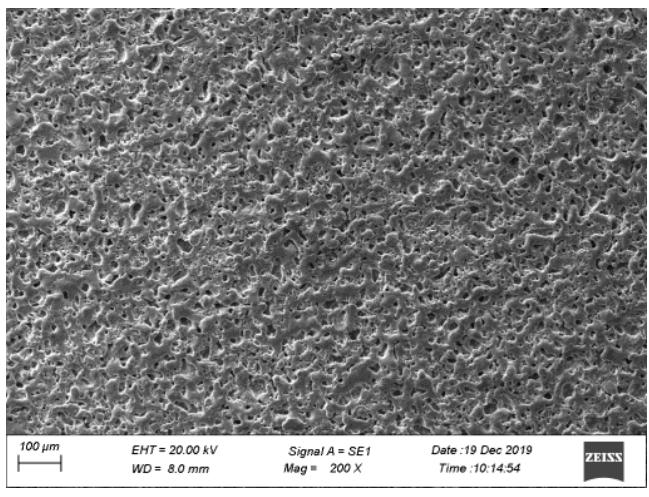

(a) Peak current 5.6A

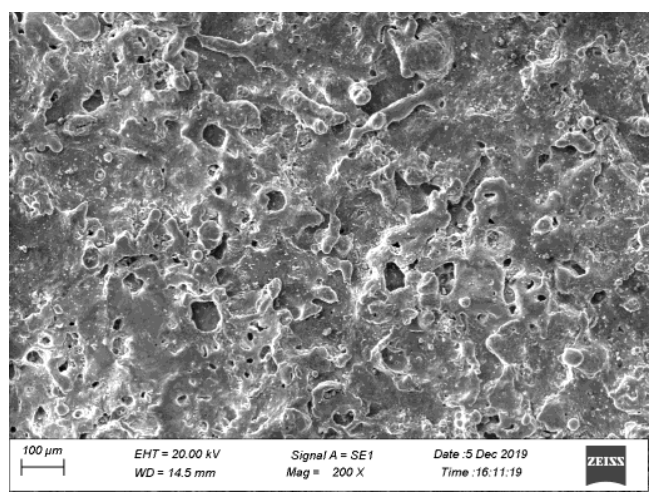

(c) Peak current 37A

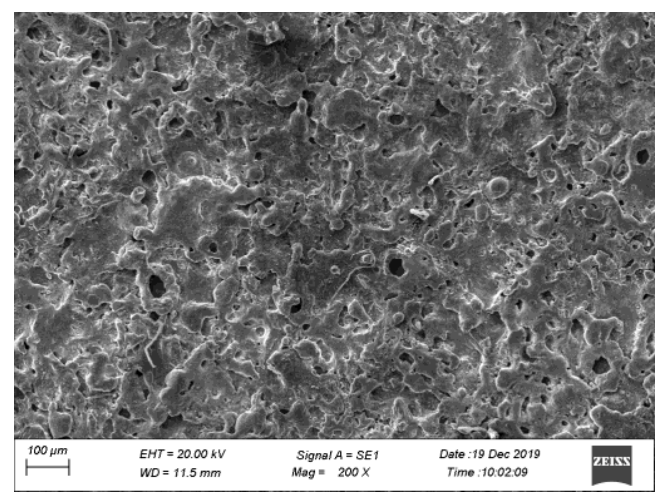

(b) Peak current $18.4 \mathrm{~A}$

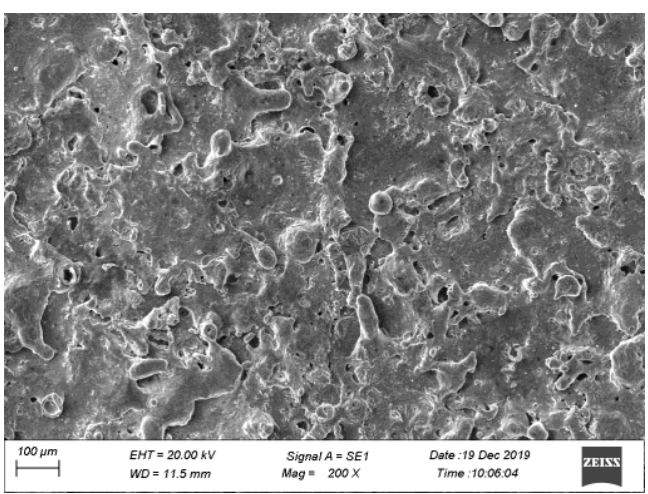

(d) Peak current 50A 


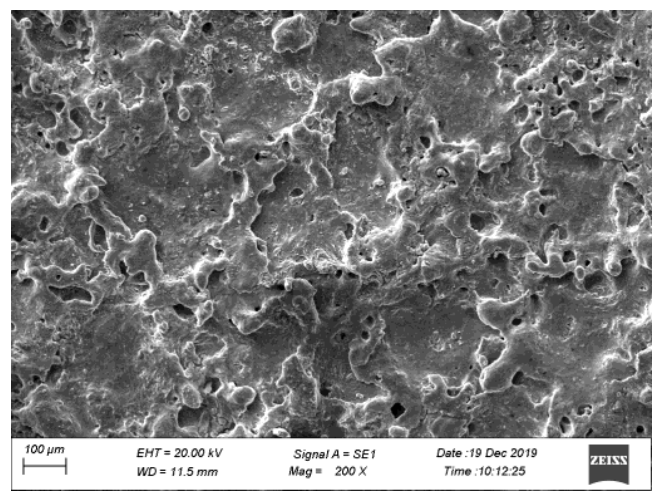

(e) Peak current $64 \mathrm{~A}$

Figure 6 Micro-topography at different currents

As the peak current increases, the energy of a single pulse discharge increases. Therefore, the energy obtained by the surface of the workpiece per unit time becomes more. In addition, the pits on the surface of the workpiece will be larger or deeper, resulting in the increase of MRR and surface roughness. With the increase of the peak current, the particles of erosion produced per unit time increase, making it difficult for the particles of erosion to exit the discharge gap from the side. The phenomenon of secondary discharge increases, the width overcut will also become larger. The difficulty in discharging the erosion particles will cause a large amount of accumulation of erosion particles and the tool electrode to frequently produce secondary discharges, and therefore increasing the RTWR.

\subsection{Effect of reference voltage on UEDM}

Under the premise that other experimental conditions remain unchanged, the size of the reference voltage change, and its influence on the MRR, surface roughness, width overcut, and RTWR is studied. Figure 7 is the relationship curve between the reference voltage and the UEDM index. We can see from the figure that as the reference voltage increases, the workpiece MRR, surface roughness, and width overcut are gradually reduced, while the RTWR gradually increases. Figure 8 is the microscopic surface morphology of UEDM square holes formed in SiCp/Al composite materials at different reference voltages. 


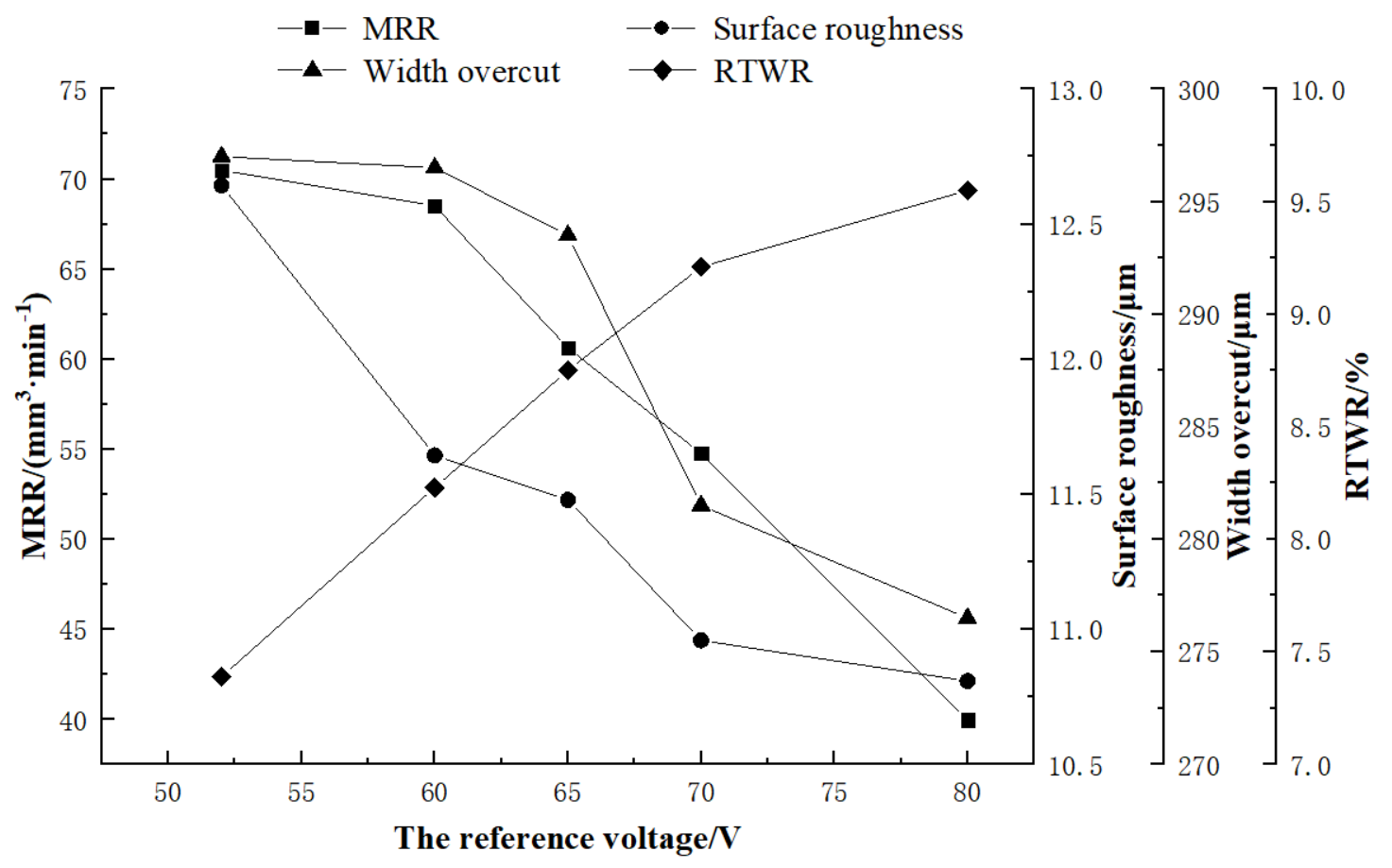

Figure 7 The influence law of reference voltage on processing index

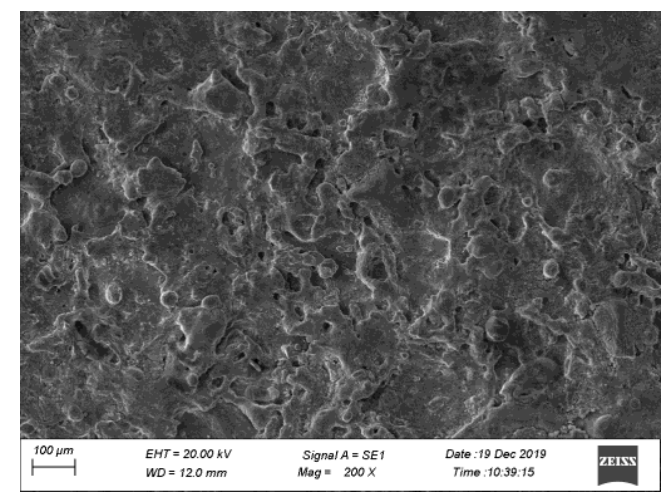

(a) The reference voltage $52 \mathrm{~V}$

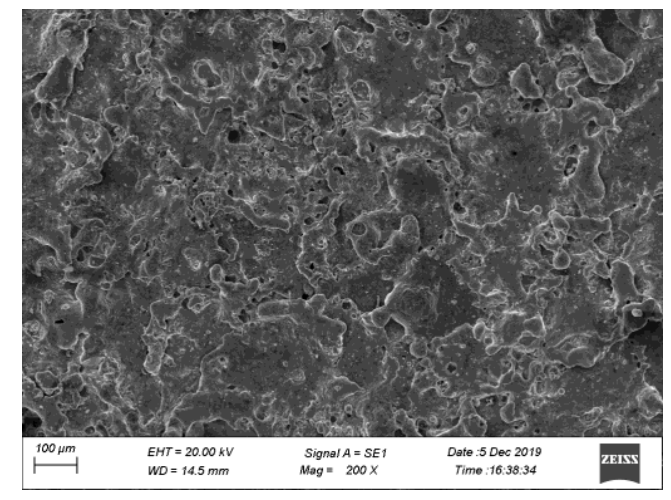

(c) The reference voltage $65 \mathrm{~V}$

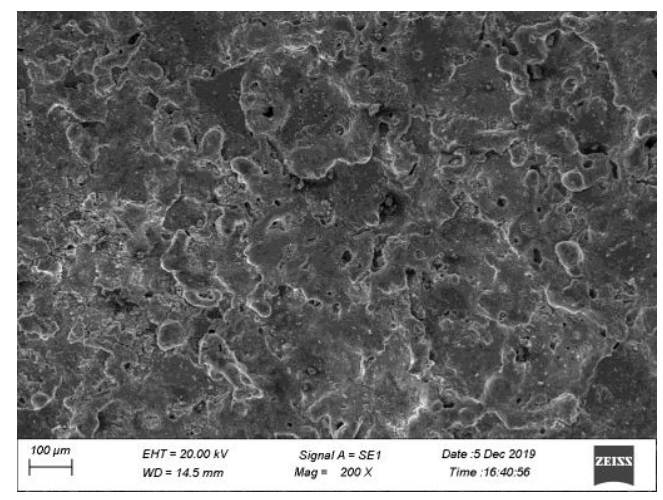

(b) The reference voltage $60 \mathrm{~V}$

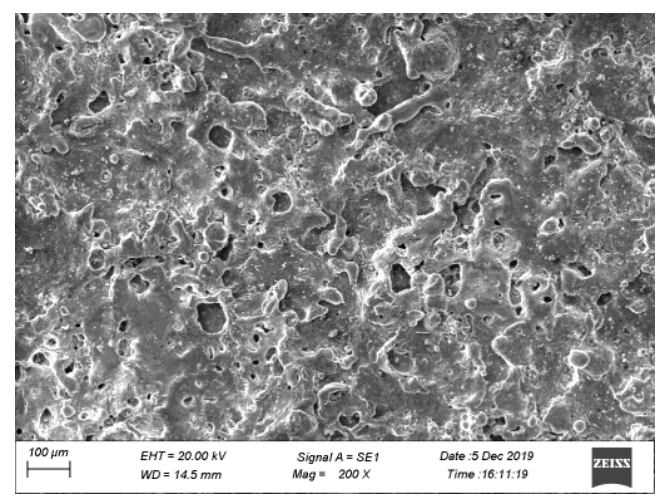

(d) The reference voltage $70 \mathrm{~V}$ 


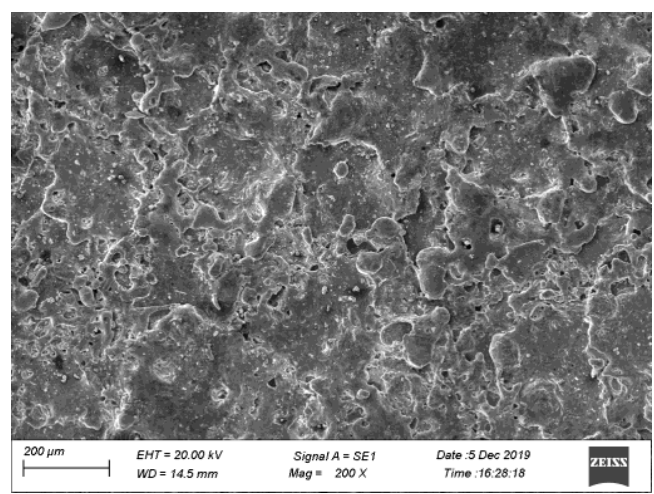

(e) The reference voltage $80 \mathrm{~V}$

Figure 8 Micro-topography at different voltages

As the reference voltage increases, the gap between the two poles increases, and the number of open circuits during processing increases, so that the effective pulse discharge per unit time decreases and the MRR of the workpiece decreases. In addition, the increase of the gap between the two poles is also conducive to the discharge of erosion particles, reducing short-circuit arcing and other phenomena, so that the surface quality of the workpiece becomes better, and the roughness value is reduced accordingly. The chip removal conditions are getting better, and the secondary discharge phenomenon caused by the accumulation of erosion in the discharge gap is reduced, resulting in the reduction of width overcut. With the increase of the reference voltage, the discharge gap between the two poles increases. During discharge, the charged particles in the discharge channel have a longer distance to obtain a greater speed, which makes the kinetic energy of the charged particles increase. Because the mass of positive ions is much greater than that of electrons, the kinetic energy obtained by positive ions is much greater than that of electrons. Therefore, when the reference voltage increases, the increase in the loss of the positive ions to the electrode is greater than the increase in the erosion of the workpiece by the electrons so that the RTWR increases.

\subsection{Effect of pulse interval on UEDM}

In UEDM, the pulse interval will affect the deionization effect of working fluid between the electrodes. Under the premise that other experimental conditions remain unchanged, change the size of the pulse interval, and study its influence on MRR, surface roughness, width overcut, and RTWR. Figure 9 is the relationship curve between pulse interval and UEDM index. It can be seen from the figure that the MRR, surface roughness, and width overcut of the workpiece gradually decrease with the increase of the pulse interval. RTWR shows a wavy change with the pulse 
interval but the overall change is small. Taking into account the influence of the error, the pulse interval in this experiment has little effect on RTWR. Figure 10 is the microscopic surface morphology of the square hole formed by UEDM in SiCp/Al composite material under different pulse interval values.

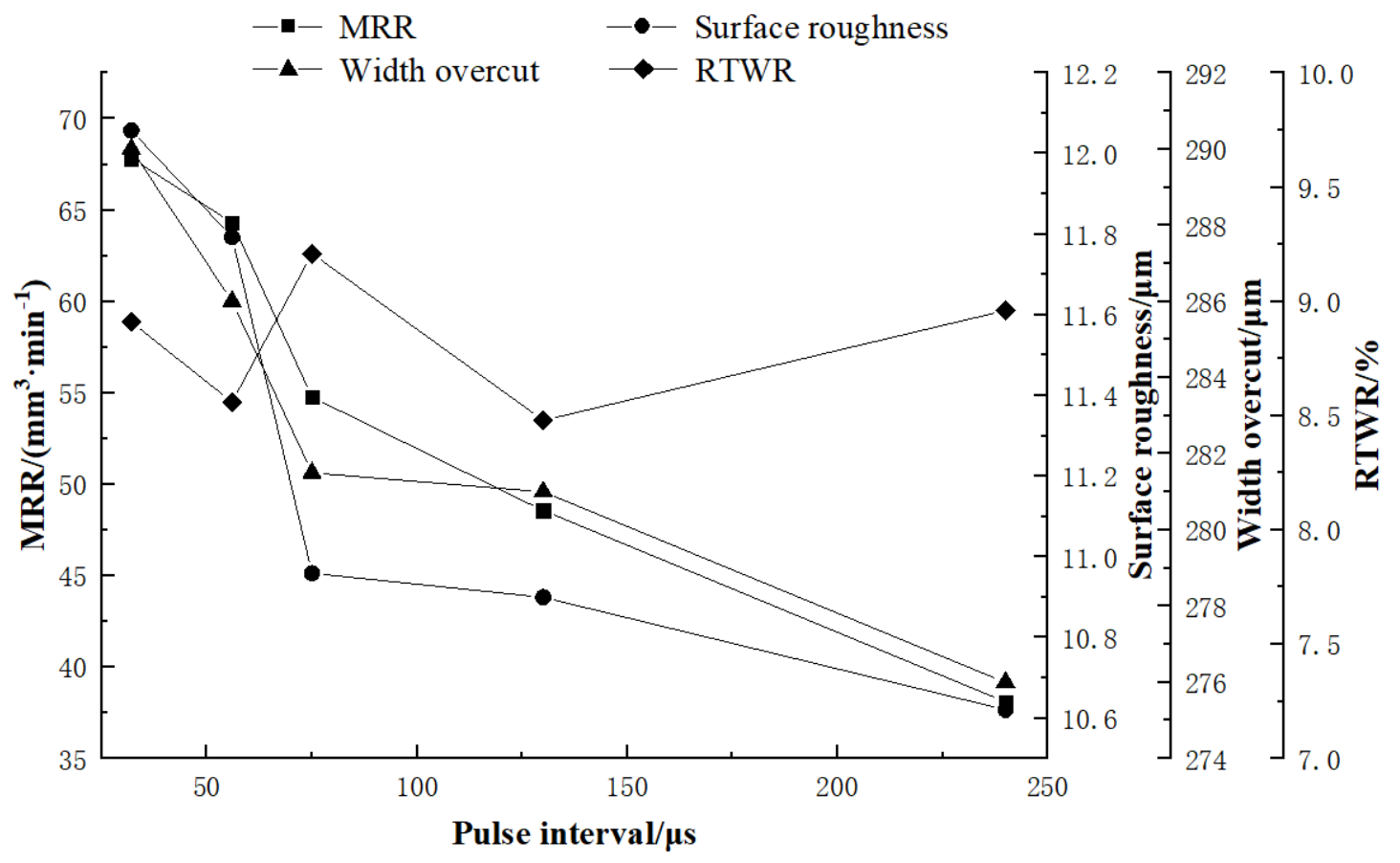

Figure 9 The influence of pulse interval on processing index

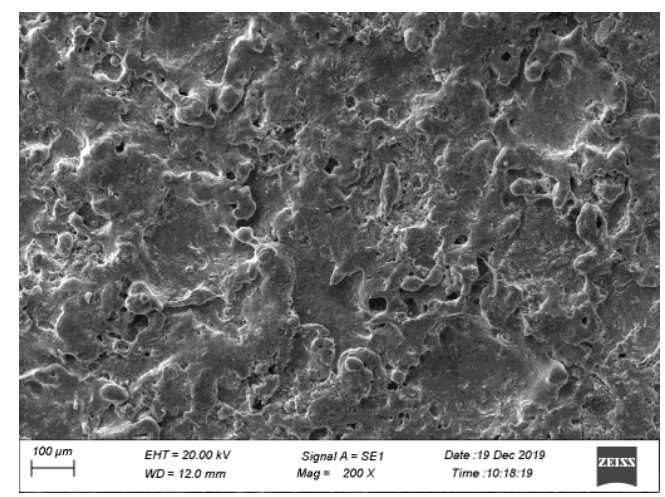

(a) Pulse interval $32 \mu \mathrm{s}$

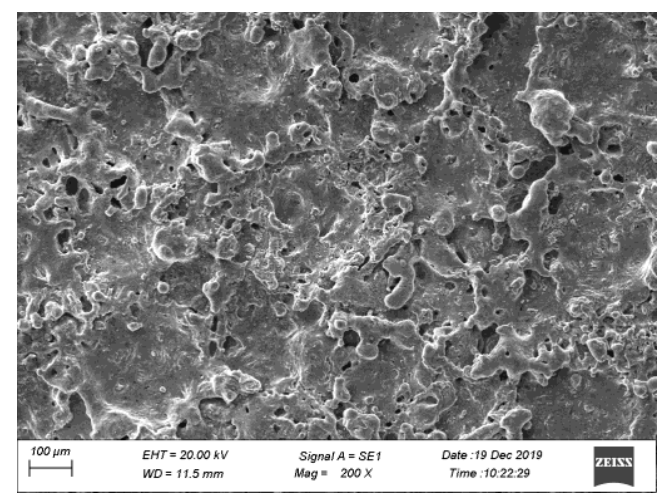

(b) Pulse interval $56 \mu \mathrm{s}$ 


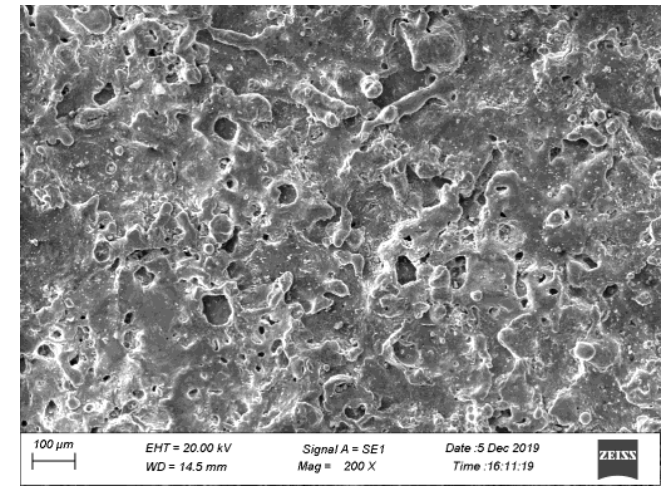

(c) Pulse interval $75 \mu \mathrm{s}$

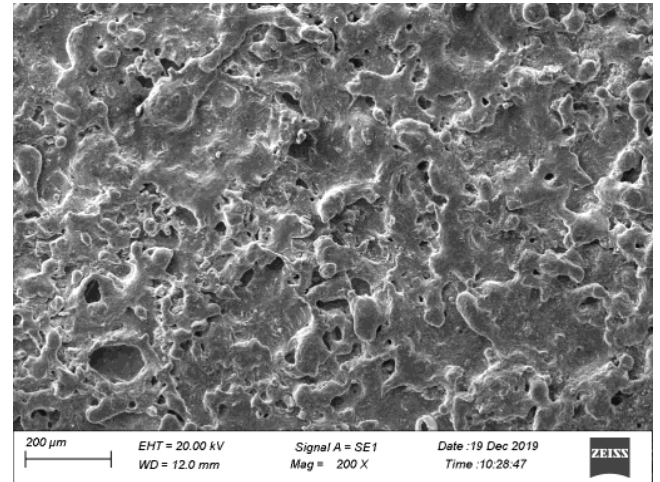

(d) Pulse interval $130 \mu \mathrm{s}$

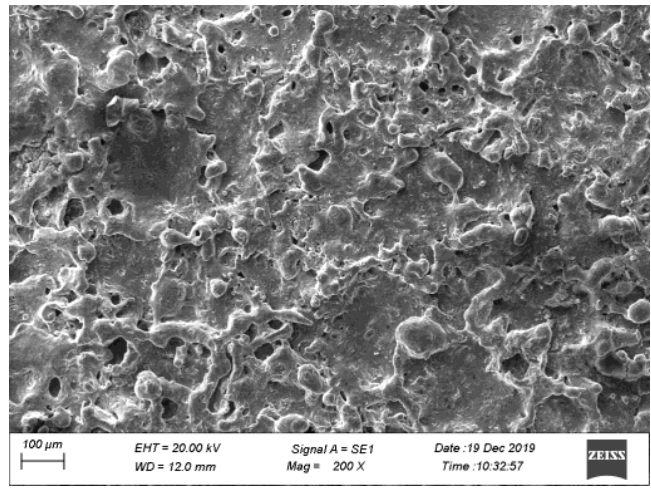

(e) Pulse interval $240 \mu \mathrm{s}$

Figure 10 Micro-topography of different pulse intervals

As the pulse interval increases, the number of pulse discharges decreases, which results in a decrease in MRR. With the increase of the pulse interval, the deionization becomes sufficient. The eroded aluminum matrix material and $\mathrm{SiC}$ particles also have more time to drain the processing gap, and the abnormal processing phenomena such as short circuit and arc drawing are reduced. The more stable is the processing, the smaller are the surface roughness and width overcut of the material. When the pulse interval continues to increase to $75 \mu \mathrm{s}$, the deionization and the discharge of the erosion will be relatively sufficient, which will cause the increase of the pulse interval to have a relatively small effect on the width overcut of the workpiece.and surface roughness.

\subsection{Effect of pulse interval on UEDM}

Figure 11 is the relationship curve between pulse width and MRR, surface roughness, width overcut, and RTWR. It can be seen from the figure that as the pulse width increases, the MRR first increases and then decreases, the surface roughness and width overcut gradually increase, and the RTWR first decreases and then increases. Figure 12 is the microscopic surface morphology of the square hole formed by UEDM in SiCp/Al composite material at different pulse width values. 


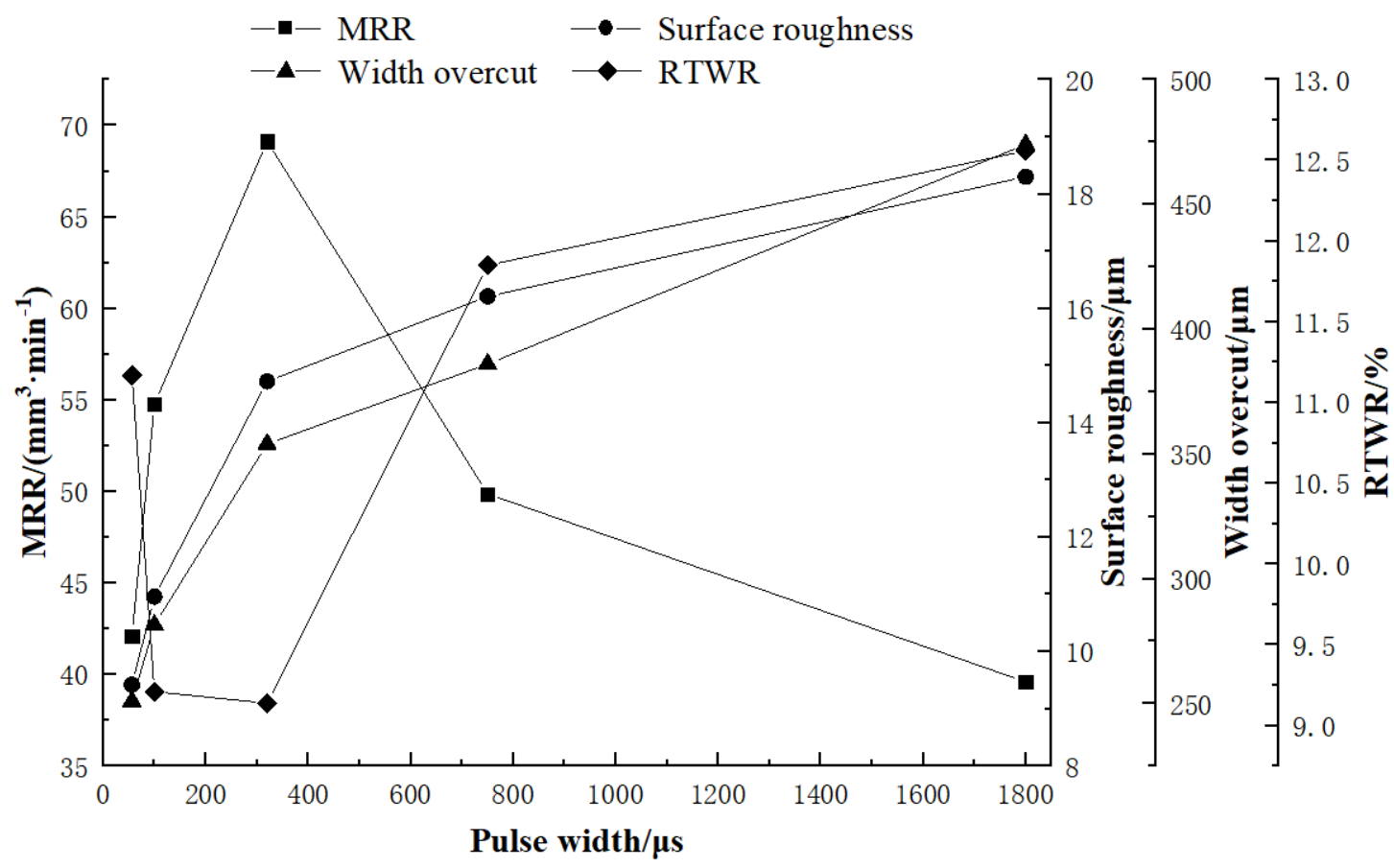

Figure 11 The influence of pulse width on processing indexes

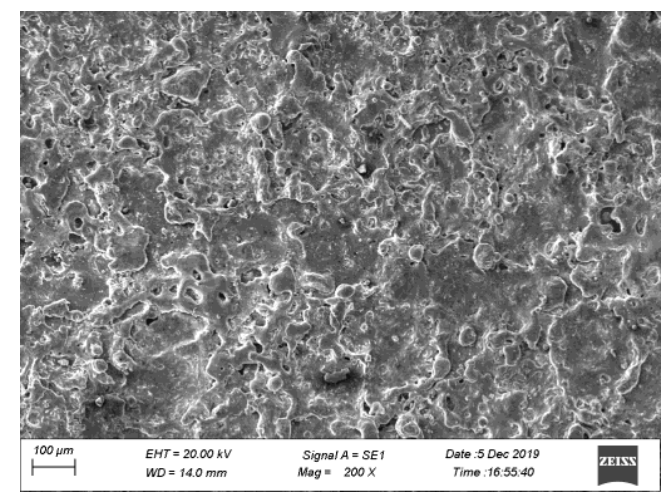

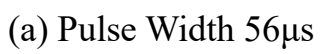

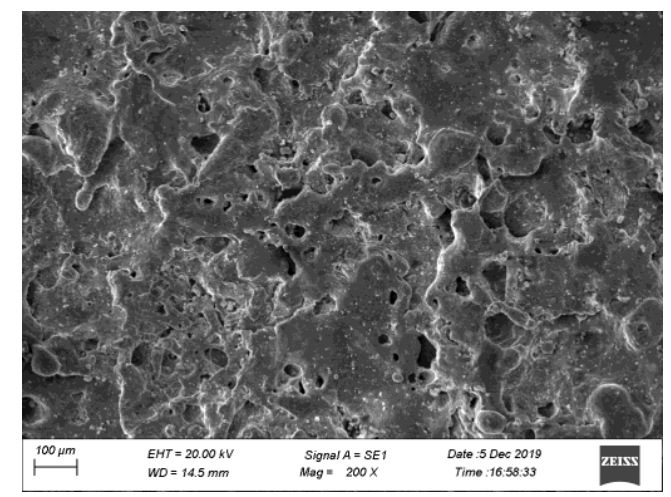

(c) Pulse Width $320 \mu \mathrm{s}$

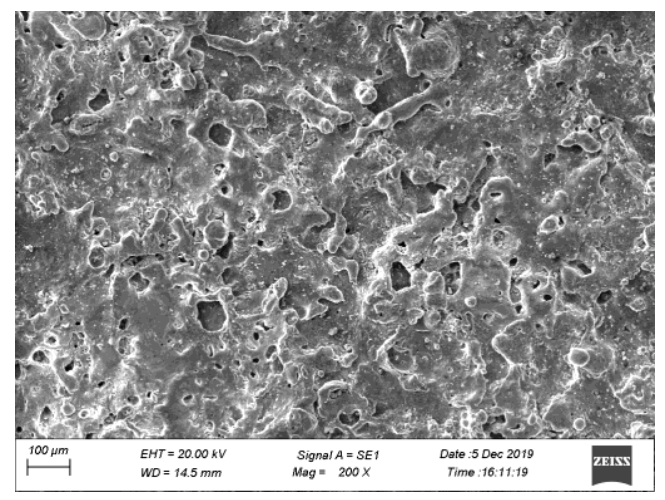

(b) Pulse Width $100 \mu \mathrm{s}$

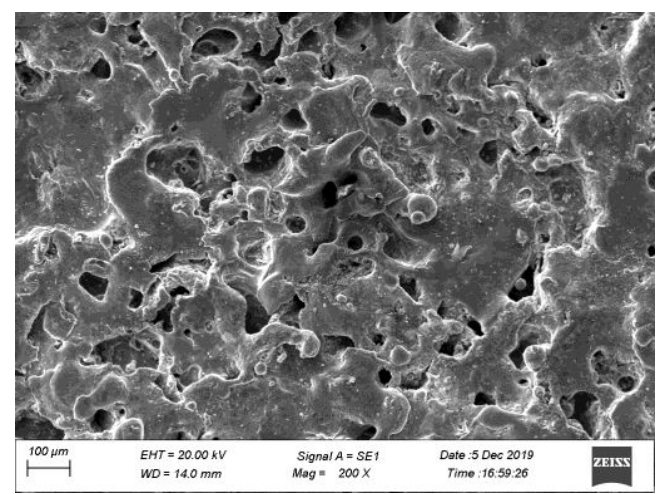

(d) Pulse Width $750 \mu \mathrm{s}$ 


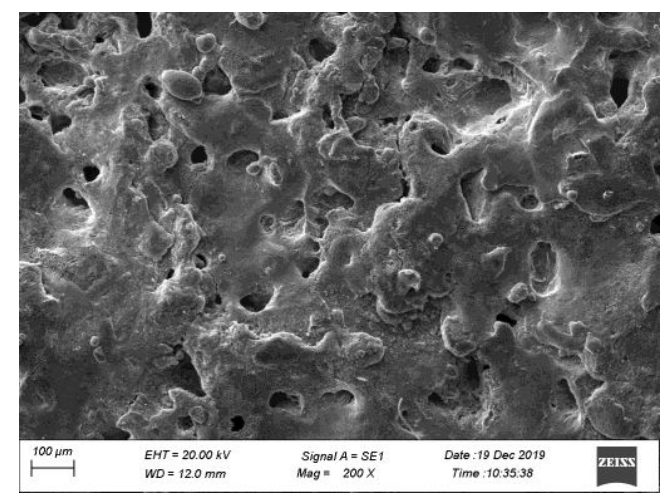

(e) Pulse Width $1800 \mu \mathrm{s}$

Figure 12 Micro-topography at different pulse widths

When the pulse width is in a smaller range, as the pulse width increases, the pulse discharge time per unit time is prolonged, the surface of the workpiece can get more heat, and the MRR of the workpiece increases. But with the pulse width continues to increase, under the heat generated by the long-term pulse discharge, the low-melting aluminum matrix material will melt in a large amount, and many $\mathrm{SiC}$ particles will fall out of the matrix. A large amount of erosions in the discharge gap makes the discharge state worse. Frequent occurrence of abnormal discharge phenomenon causes the MRR to decrease. Therefore, as the pulse width increases, the MRR first increases and then decreases. As the pulse width increases, the energy of a single pulse discharge increases, and the amount of erosion processed by a single discharge increases. The pits on the surface of the workpiece will be larger or deeper, which will eventually lead to the roughness of the processed surface increasing accordingly. At the same time, as the pulse width increases, the number of materials to be eroded increases, and frequent secondary discharges lead to an increase in the amount of width overcut. From Figure 11, when the pulse width is $300 \mu$ s, the RTWR reaches the minimum.

\section{Orthogonal test results and parameter optimization}

Table 5 shows the experimental results.

Table 5 Orthogonal experiment results

\begin{tabular}{ccccc}
\hline $\begin{array}{c}\text { Serial } \\
\text { number }\end{array}$ & $\begin{array}{c}\text { Material removal rate } \\
/\left(\mathrm{mm}^{3} / \mathrm{min}\right)\end{array}$ & $\begin{array}{c}\text { Surface } \\
\text { roughness } / \mu \mathrm{m}\end{array}$ & $\begin{array}{c}\text { Width } \\
\text { overcut } / \mu \mathrm{m}\end{array}$ & $\begin{array}{c}\text { Relative loss rate of } \\
\text { electrode } /(\%)\end{array}$ \\
\hline 1 & 21.383 & 8.546 & 243 & 5.01 \\
2 & 42.628 & 9.78 & 244 & 11.41 \\
3 & 22.098 & 10.55 & 228 & 20.36 \\
4 & 51.891 & 14.848 & 347 & 8.34 \\
5 & 121.837 & 17.605 & 360 & 10.63 \\
6 & 21.462 & 13.668 & 303 & 4.51 \\
7 & 69.371 & 19.238 & 502 & 17.66
\end{tabular}




\begin{tabular}{ccccc}
8 & 8.962 & 14.41 & 353 & 5.61 \\
9 & 48.032 & 16.739 & 490 & 12 \\
\hline
\end{tabular}

\subsection{Parameter optimization based on the grey relational analysis method}

\subsubsection{Calculate the gray correlation value}

In the actual production process of UEDM forming holes in $\mathrm{SiCp} / \mathrm{Al}$ composites, not only one of the above-mentioned test indicators is investigated separately, but the comprehensiveness between the various test indicators should be investigated. Therefore, this experiment is based on the grey relational analysis method to find the best combination of process parameters for the comprehensive advantages of the four process indicators. The larger the gray correlation value, the better the performance.

The gray correlation coefficient and gray correlation values are shown in Table 6.

Table 6 Gray correlation coefficient and gray correlation value

\begin{tabular}{cccccc}
\hline \multirow{2}{*}{$\begin{array}{c}\text { Test } \\
\text { number }\end{array}$} & \multicolumn{3}{c}{ Grey correlation coefficient } & Grey \\
\cline { 2 - 5 } & $\begin{array}{c}\text { Material } \\
\text { removal rate }\end{array}$ & $\begin{array}{c}\text { Surface } \\
\text { roughness }\end{array}$ & $\begin{array}{c}\text { Width } \\
\text { overcut }\end{array}$ & $\begin{array}{c}\text { Relative loss rate of } \\
\text { electrode }\end{array}$ & $\begin{array}{c}\text { Grey } \\
\text { relation }\end{array}$ \\
\hline 1 & 0.4885 & 1 & 0.9395 & 0.9642 & 0.8481 \\
2 & 0.5478 & 0.8805 & 0.9357 & 0.6613 & 0.7563 \\
3 & 0.4903 & 0.8193 & 1 & 0.4595 & 0.6923 \\
4 & 0.5784 & 0.5905 & 0.6618 & 0.7786 & 0.6523 \\
5 & 1 & 0.5008 & 0.6383 & 0.6876 & 0.7067 \\
6 & 0.4887 & 0.6396 & 0.7564 & 1 & 0.7212 \\
7 & 0.6465 & 0.4595 & 0.4595 & 0.5061 & 0.5179 \\
8 & 0.4595 & 0.6078 & 0.6507 & 0.9245 & 0.6606 \\
9 & 0.5652 & 0.5259 & 0.4706 & 0.6427 & 0.5511 \\
\hline
\end{tabular}

Obtained from Table 6 , when the pulse width is $56 \mu \mathrm{s}$, the pulse interval is $32 \mu \mathrm{s}$, the peak current is $18.4 \mathrm{~A}$, and the reference voltage is $60 \mathrm{~V}$, the gray correlation value reaches the maximum, which is 0.8481 .

\subsubsection{Analysis of optimal processing parameters}

According to the principle of the gray correlation analysis method, if grey relational value is the maximum value, it indicates that the process parameter makes the maximum correlation of various process indicators at this level, that is, the level is considered the four indicators reached the optimal. Respectively add up the correlation values of each process parameter at each level in Table 6 and then calculate the average value, and obtain the average value of each level under each process parameter in turn, as shown in Table 7.

Table 7 Average gray correlation value 


\begin{tabular}{cllll}
\hline Pulse width $(\mu \mathrm{s})$ & $\underline{0.7656}$ & 0.6934 & 0.5765 & 0.1891 \\
Pulse interval ( $\mu$ s) & $\underline{0.6728}$ & $\underline{0.7079}$ & 0.6549 & 0.0530 \\
Peak current $(\mathrm{A})$ & $\underline{0.7433}$ & 0.6532 & 0.6390 & 0.1043 \\
The reference voltage $(\mathrm{V})$ & $\underline{\underline{0.7020}}$ & 0.6651 & 0.6684 & 0.0369 \\
\hline
\end{tabular}

According to Table 7, when the peak current is $18.4 \mathrm{~A}$, the reference voltage is $60 \mathrm{~V}$, the pulse interval is $75 \mu \mathrm{s}$, and the pulse width is $56 \mu \mathrm{s}$. This group of processing parameters is the optimal processing parameters. In addition, the order of the impact on the overall performance from large to small is pulse width, peak current, pulse to pulse and reference voltage.

\subsection{Verification experiment}

The parameters of the verification experiment are the optimal combination of processing parameters found by the grey relational analysis method. In the verification test, the factors other than the four processing parameters are strictly controlled to be the same as the orthogonal test settings. Through data analysis before and after processing, the results are: the MRR of the workpiece is $21.192 \mathrm{~mm}^{3} / \mathrm{min}$, the surface roughness Ra is $8.114 \mathrm{um}$, the width overcut is $235 \mathrm{um}$, and the RTWR is $5.285 \%$. Calculating the gray correlation value of the results obtained from the verification experiment, the calculated value reaches the maximum. The gray correlation value reaches 0.8511 , which is greater than the maximum gray correlation value of 0.8481 obtained by the orthogonal experiment. Therefore, the optimized parameter combination is the optimal processing parameter combination scheme.

\section{Conclusion}

This paper analyzes the influence of ultrasonic vibration on EDM from the machining mechanism, and carried out theoretical analysis and simulation calculation on the flow field of machining gap. With the aid of ultrasonic vibration, the single factor test of SiCp/Al composite forming machining was carried out on the UEDM test platform. The effects of peak current, reference voltage, pulse interval and pulse width on MRR, width overcut, surface roughness and the RTWR were explored. Through orthogonal experiment, combined with gray correlation method, the combination of processing parameters that makes the comprehensive performance of processing indexes reach the best is obtained. The specific conclusions are as follows:

(1) The effect of tool electrode on the discharge channel, discharge gap, erosion material discharge and machined surface in EDM after ultrasonic vibration is analyzed. The analysis results show that the periodic ultrasonic vibration of the tool electrode can effectively reduce the occurrence of unstable processing, and can improve the processing efficiency and the surface quality of the workpiece.

(2) With the help of FLUENT, the law of the velocity change of the flow field in the machining gap and the discharge of the erosion particles are solved. It is concluded that the ultrasonic vibration of the tool electrode can accelerate the flow rate of the working fluid in the discharge gap, promote the removal of erosion particles from the processing gap, and prevent erosion particles from accumulating in the discharge gap. 
(3) On the UEDM test platform, single-factor experiment of forming square holes in $\mathrm{SiCp} / \mathrm{Al}$ composites was carried out. The research results show that with the increase of the peak current, the MRR, surface roughness, and width overcut and RTWR show a gradually increasing trend. With the increase of the reference voltage, the MRR, surface roughness and width overcut show a gradually decreasing trend, while the RTWR is gradually decreasing. With the increase of the pulse interval, the MRR, surface roughness, and width overcut show a gradually decreasing trend. With the increase of the pulse width, the MRR shows a trend of increasing first and then decreasing, the surface roughness and the width overcut show a gradually increasing trend, and the RTWR shows a trend of first decreasing and then increasing.

(4) Based on the single factor test, the orthogonal test of UEDM machining SiCp/Al composite material hole was carried out, and the combination of gray correlation analysis method was used to find the combination of processing parameters that maximized the comprehensive performance of the four processing indicators. The peak current is $18.4 \mathrm{~A}$, the reference voltage is $60 \mathrm{~V}$, the pulse interval is $75 \mu \mathrm{s}$, and the pulse width is $56 \mu \mathrm{s}$, which is the optimal combination of processing parameters.

\section{Declarations}

(1)Funding

The National Nature Science Foundation of China (NSFC) (Grant No. 51775316).

(2) Conflict of interest/ Competitive interests

The authors have no financial or proprietary interests in any material discussed in this article.

(3)Availability of data and material

Not applicable

(4) Code availability

Not applicable

(5)Ethics approval

Not applicable

(6) Consent to participate

Not applicable

(7) Consent for publication

Not applicable

\section{References}

[1] Yu, X., Huang, S., \& Xu, L. (2016). Elid grinding characteristics of sicp/al composites. INTERNATIONAL JOURNAL OF ADVANCED MANUFACTURING TECHNOLOGY, 86(5-8), $1165-1171$.

[2] Chen, Z., Zhou, H., Yan, Z., Han, F., \& Yan, H. (2021). Machining characteristics of 65 vol. \% sicp/al composite in micro-wedm. Ceramics International (6). 
[3] Dong, Z., Zheng, F., Zhu, X., Kang, R., Zhang, B., \& Liu, Z. (2017). Characterization of material removal in ultrasonically assisted grinding of sicp/al with high volume fraction. International Journal of Advanced Manufacturing Technology.

[4] Azat, Bilal, Muhammad, Pervej, Jahan, \& Didier, et al. (2018). Electro-discharge machining of ceramics: a review. Micromachines.

[5] Zhang, H., HUFuqiang, Chen, H., \& WUGaohui. (2009). Study on the machining of micro pore on sicp/al composites by edm. Manufacturing Technology \& Machine Tool.

[6] Liu, Y., Wang, B., Zhang, W. Zhang, S., \& Sha, Z. (2019). Study on thermal erosion process of sic $\mathrm{p} / \mathrm{al}$ composite material in edm. IOP Conference Series Materials Science and Engineering, 692, 012012.

[7] Senapati, N. P., Kumar, R., Tripathy, S., \& Rout, A. (2017). Multi-objective optimization of edm process parameters using pca and topsis method during the machining of al-20\%sic p metal matrix composite. Springer Singapore.

[8] Jiang, S., Qi, L. I., \& Yang, X. (2019). Temperature field simulation of sicp/al in pmedm. Electromachining \& Mould.

[9] Hu, F. Q. , Song, B. Y. , Guo, Y. F. , Yang, X. D. , Bai, J. C. , \& Li, D. . (2011). Study on powder mixed edm of an aluminium matrix composite. Advanced Materials Research, 183-185, 1947-1951.

[10] Lin, Y. C., Chuang, F. P., Wang, A. C., \& Chow, H. M. (2014). Machining characteristics of hybrid edm with ultrasonic vibration and assisted magnetic force. International Journal of Precision Engineering \& Manufacturing, 15(6), 1143-1149.

[11] Liao, Y. S., Wu, P. S., \& Liang, F. Y. (2013). Study of debris exclusion effect in linear motor equipped die-sinking edm process. Procedia CIRP, 6(7), 123-128.

[12] Liu, Y., Chang, H., Zhang, W., Ma, F., Sha, Z., \& Zhang, S. (2018). A simulation study of debris removal process in ultrasonic vibration assisted electrical discharge machining (edm) of deep holes $\dagger$. Micromachines, 9(8).

[13] Wang, Y., Liu, Z., Shi, J., Dong, Y., Yang, S., Zhang, X., \& Lin, B. (2020). Analysis of material removal and surface generation mechanism of ultrasonic vibration-assisted EDM. The International Journal of Advanced Manufacturing Technology, 110(1), 177-189.

[14] Shabgard, M. R., Gholipoor, A., \& Mohammadpourfard, M. (2018). Numerical and 
experimental study of the effects of ultrasonic vibrations of tool on machining characteristics of edm process. International Journal of Advanced Manufacturing Technology.

[15] Shitara, T., Fujita, K., \& Yan, J. (2020). Direct observation of discharging phenomena in vibration-assisted micro-electrical discharge machining. International Journal of Advanced Manufacturing Technology, 108(4).

[16] Shervani-Tabar, M. T., Abdullah, A., \& Shabgard, M. R. (2007). Numerical and experimental study on the effect of vibration of the tool in ultrasonic assisted edm. The International Journal of Advanced Manufacturing Technology, 32(7-8), 719-731.

[17] N Sabyrov, Jahan, M., Bilal, A., \& Perveen, A. (2019). Ultrasonic vibration assisted electrodischarge machining (edm)—an overview. Materials, 12(3).

[18] Goiogana, M., Sarasua, J. A., Ramos, J. M., Echavarri, L., \& I Cascón. (2016). Pulsed ultrasonic assisted electrical discharge machining for finishing operations. International Journal of Machine Tools and Manufacture, 87-93.

[19] Pragadish, N., \& Kumar, M. P. (2016). Optimization of dry edm process parameters using grey relational analysis. Arabian Journal for Science \& Engineering, 41(11), 1-8.

[20] L An. (1995). Research on Gap Characteristics of EDM Finish Machining. Machinery Design \& Manufacture, 000(002), 48-50. (In Chinese). 